\title{
Improving osteoarthritis management in primary healthcare: results from a quasi- experimental study
}

\author{
Nina Østerås ${ }^{1 *}$ (D), Irma Brandeggen Blaker ${ }^{2}$, Tore Hjortland ${ }^{3}$, Elizabeth Cottrell ${ }^{4}$, Jonathan G. Quicke ${ }^{4}$, \\ Krysia S. Dziedzic ${ }^{4}$, Steven Blackburn ${ }^{4}$ and Aksel Paulsen ${ }^{5,6}$
}

\begin{abstract}
Background: To improve quality of care for patients with hip and knee osteoarthritis (OA), general practitioners (GPs) and physiotherapists (PTs) in a Norwegian municipality initiated an intervention. The intervention aimed to increase provision of core OA treatment (information, exercise, and weight control) prior to referral for surgery, rational use of imaging for assessing $\mathrm{OA}$ and improve communication between healthcare professionals. This study assessed the effectiveness of this intervention.
\end{abstract}

Methods: Forty-eight PTs and one hundred one GPs were invited to the intervention that included two interactive workshops outlining best practice and an accompanying template for PT discharge reports. Using interrupted time series research design, the study period was divided into three: pre-implementation, transition (implementation) and post-implementation. Comparing the change between pre- and post-implementation, the primary outcome was patient-reported quality of OA care measured with the OsteoArthritis Quality Indicator questionnaire. Secondary outcomes were number of PT discharge reports, information included in GP referral letters to orthopaedic surgeon, the proportion of GP referral letters indicating use of core treatment, and the use of imaging within OA assessment. Analyses involved linear mixed and logistic regression models.

Results: The PT workshop had 30 attendees, and 31 PTs and 33 GPs attended the multidisciplinary workshop. Two hundred eight and one hundred twenty-five patients completed the questionnaire during pre- and post-implementation, respectively. The adjusted model showed a small, statistically non-significant, increase in mean total score for quality of OA care (mean change $=4.96,95 \% \mathrm{Cl}-0.18,10.12$, p:0.057), which was mainly related to items on OA core treatment. Patients had higher odds of reporting receipt of information on treatment alternatives (odds ratio (OR) 1.9, 95\% Cl 1.08, 3.24) and on selfmanagement (OR 2.4, 95\% Cl 1.33, 4.32) in the post-implementation phase. There was a small, statistically non-significant, increase in the proportion of GP referral letters indicating prior use of core treatment modalities. There were negligible changes in the number of PT discharge reports, in the information included in the GP referral letters, and in the use of imaging for $\mathrm{OA}$ assessment.

Conclusion: This study suggests that a primary care intervention including two inter-active workshops can shift the quality of care towards best practice recommendations.

(Continued on next page)

\footnotetext{
* Correspondence: nina.osteras@medisin.uio.no

${ }^{1}$ Division of Rheumatology and Research, National Advisory Unit on Rehabilitation in Rheumatology, Diakonhjemmet Hospital, Oslo, Norway

Full list of author information is available at the end of the article
}

C The Author(s). 2021 Open Access This article is licensed under a Creative Commons Attribution 4.0 International License, which permits use, sharing, adaptation, distribution and reproduction in any medium or format, as long as you give appropriate credit to the original author(s) and the source, provide a link to the Creative Commons licence, and indicate if changes were made. The images or other third party material in this article are included in the article's Creative Commons licence, unless indicated otherwise in a credit line to the material. If material is not included in the article's Creative Commons licence and your intended use is not permitted by statutory regulation or exceeds the permitted use, you will need to obtain permission directly from the copyright holder. To view a copy of this licence, visit http://creativecommons.org/licenses/by/4.0/. The Creative Commons Public Domain Dedication waiver (http://creativecommons.org/publicdomain/zero/1.0/) applies to the data made available in this article, unless otherwise stated in a credit line to the data. 
(Continued from previous page)

Trial registration: ClinicalTrials.gov: NCT02876120.

Keywords: Osteoarthritis, Implementation, Quality of care

\section{Background}

Osteoarthritis $(\mathrm{OA})$ is a serious joint disease characterized by pain, disability, and impaired quality of life. Prevalence of OA increases with age, and nearly one in two people will develop symptomatic knee OA and one in four symptomatic hip OA in their lifetime $[1,2]$. With an aging population and the epidemic of obesity, the prevalence of $\mathrm{OA}$ is set to rise [3]. OA is one of the leading causes of pain and disability for the adult population worldwide [4] and one of the major contributors to years lived with disability [5]. The costs of treatment and work-related losses represent a considerable economic burden [6, 7].

Recommended first-line, core treatments include patient education, self-management, exercise, and weight reduction [4, 8-10]. These core interventions can reduce pain and improve function and should be offered to all individuals with symptomatic OA. Joint replacement offers an effective option for those with pain and reduced function that has a substantial impact on their quality of life and are refractory to non-surgical treatment [11]. However, it is costly and associated with medical and surgical risks [12-15], and although most patients benefit greatly from the operation [16-18], it is not always effective [19]. One in ten hip and one in five knee joint replacements have painful joints postoperatively [20]. Due to the increasing prevalence of OA, the demand for joint replacements is expected to accelerate and quadruple by 2030 [21]. Since it is estimated that only $12-53 \%$ of patients with symptomatic OA should be offered arthroplasties [22], it is important to improve the uptake of high-quality non-surgical care. In addition, previous research has suggested an overuse of resource intensive Magnetic Resonance Imaging (MRI) in the diagnosis and treatment of moderate to severe OA [23]. Since decisions on joint replacement can be made using the less resource intensive conventional radiographs, and use of Magnetic Resonance Imaging (MRI) is usually unnecessary [24], this resource overuse should be addressed.

Evidence based recommendations and standards of care for OA management have existed, and remained consistent, for over a decade $[4,8-10]$, but provided care often does not align well with recommended treatment modalities [25-27]. This is particularly evident for the core treatments. Among physiotherapists' (PTs) practice, exercise treatment is frequently provided, but PTs also tend to provide several other treatment modalities with no evidence or moderate to low quality of evidence (e.g., acupuncture, electrotherapy) [28-31]. In order to provide best value
OA care, it is important to both implement evidence based cost-effective care and reduce the use of care with no or limited evidence and at the same time rationalize resource use (e.g., use group-based treatments). Previous research indicate that both general practitioners (GPs) and PTs are reluctant to discuss weight issues with their patients [32-34]. It has also been shown that GPs favoured monitoring patients' physical function, pain and analgesia use over body mass index (BMI), self- management plans and exercise advice [35]. Indeed, some GPs feel they have insufficient expertise to advise patients about exercise [36]. Further, few Norwegian PTs send discharge reports routinely [37], which may limit the GPs' knowledge on effects of physical therapy and restrain the communication between health professionals.

A small number of best practice initiatives to improve quality of $\mathrm{OA}$ care have been conducted with diverging results [38-44]. The current study, the STavanger osteoARThritis (START) study, was initiated by a group of clinicians (GP, PT, and orthopaedic surgeon) working in primary and specialist healthcare services. The purpose of START was to employ an intervention to increase the communication between GPs and PTs, to improve the quality of $\mathrm{OA}$ care by implementing evidence-based treatment recommendations for OA care, and to evaluate the impact of the intervention on: 1) alignment of care with guideline recommendations, 2) frequency of PTs providing discharge reports to the GPs through provision of a template for discharge report, 3) frequency of GP referral letters to orthopaedic surgeons including pre-defined relevant information, 4) frequency of GP referral letters indicating prior use of core treatment, and 5) frequency of GP referral letters indicating that the patient had an MRI taken, and not a conventional radiograph, for decision making about joint replacement surgery.

\section{Methods \\ Design and setting}

The START study, undertaken between September 2016 and November 2017, employed an interrupted time series design, which is considered to be the strongest quasi-experimental research design [45]. The study was conducted in Stavanger Municipality, Norway, which has a population of approximately 130,000 inhabitants. It represents a collaborative study between GPs and PTs in Stavanger primary healthcare, an orthopaedic surgeon at the Department of orthopaedics at Stavanger University 
Hospital, and researchers at National Advisory Unit on Rehabilitation in Rheumatology at Diakonhjemmet Hospital, Oslo. The START study was prospectively registered at clinicaltrials.gov (NCT02876120) and is reported according to the TREND checklist [46]. The START study was linked to the "Joint Implementation of Guidelines for oSteoArthritis in Western Europe" (JIGSAW-E) implementation approach (https://jigsaw-e. $\mathrm{com} /$ ) which was based upon the MOSAICS study [47] where implementation science and knowledge mobilisation theory (e.g. Normalisation Process Theory, implementation theory, the Theoretical Domains Framework and principles of adult learning) was used to guide implementation.

The START study was divided into three periods: preimplementation, transition (implementation) and postimplementation period (Fig. 1). The data collection took place during pre- and post-implementation periods, with each lasting 8 weeks. The intervention was implemented during the transition period, which lasted 44 weeks. The transition period was planned to be long to give the healthcare professionals time to implement the intervention and change their practice. This way, the data collection in the pre- and post-implementation periods took place at the same time of the year (autumn).

The Regional Committee for Medical and Health Research Ethics (Ref. no.: 2016/1734 REK South-East D) and The Data Inspectorate/ Data Protection Official at Stavanger University Hospital (Ref. no.: 2016/31) approved the study.

\section{Participants}

All GPs and PTs working in private practice in Stavanger Municipality who saw adults with OA were invited to participate in the study. The GPs received a written invitation from the Stavanger Municipality Chief Medical Officer to attend a multidisciplinary workshop. Two of the PTs in the project group visited all PT clinics and invited the PTs to attend the PT workshop and the multidisciplinary workshop. Patient participants were recruited by the PTs during the pre- and the postimplementation periods. The pre- and the postimplementation participants were different patients. All patients that had received physiotherapy treatment for at least 2 weeks (4-6 sessions) due to symptomatic hip and/or knee OA fulfilled the inclusion criterion. All patients with language- or other impairments disqualifying completion of patient-reported quality of OA care questionnaire were excluded.

\section{Blinding}

The GPs, PTs and patient participants were informed on the purpose of the study, but they remained blinded regarding the study outcome measures.

\section{Intervention}

The intervention intended to facilitate communication between health professionals in primary healthcare and with healthcare professionals in specialist healthcare to ensure that people with hip and knee OA would experience timely, well integrated, and high-quality OA care (Fig. 2). The intervention included a PT workshop and a multidisciplinary workshop and was linked to the JIGSAW-E project (https://jigsaw-e.com/) and inspired by the SAMBA study [48] . The aim of JIGSAW-E was the implementation of an approach to improve the quality of care and to support self-management of OA in primary care. The JIGSAW-E approach includes four innovations: 1) an OA guidebook written by patients and health professionals, 2) a model consultation for diagnostic and follow-up consultations, 3) training for health professionals delivering the care, and 4) quality indicator recording and measurement tools. The SAMBA study intervention included a PT workshop and a multidisciplinary workshop to implement a model for structured OA care in primary health care. Compared to the JIGSAW-E and the SAMBA interventions, the STAR $\mathrm{T}$ study included some new elements: distribution of a

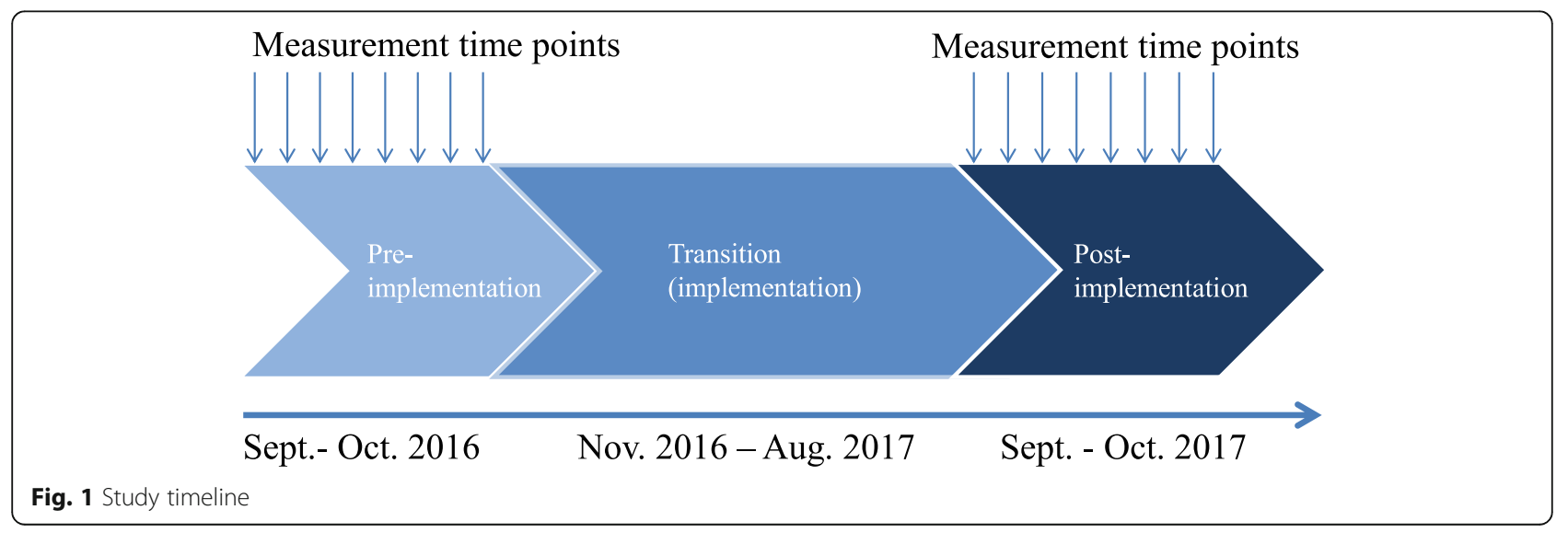



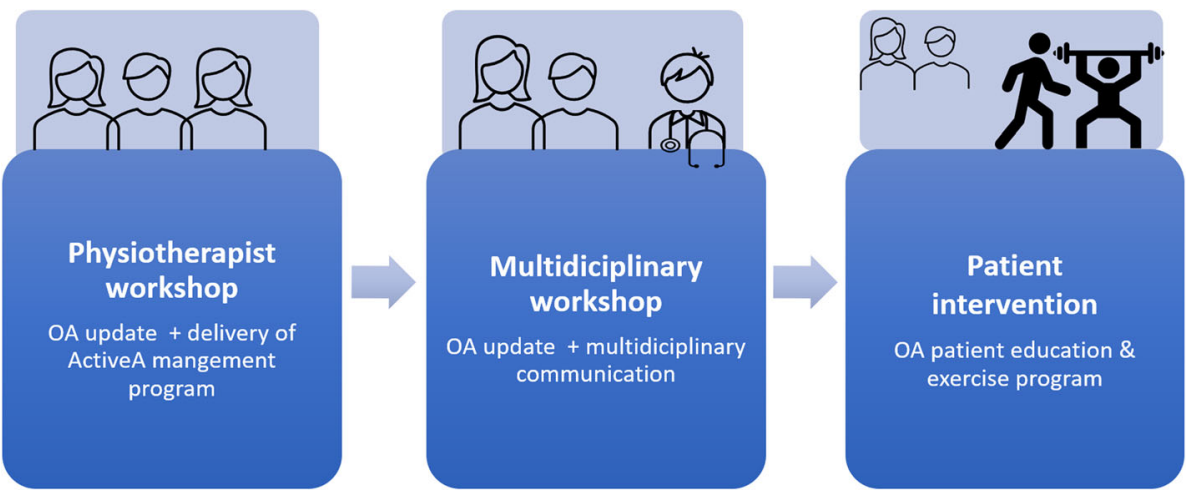

Fig. 2 Overview of the intervention components

template for PT discharge reports and a discussion on indications for joint replacement, and a focus on the content of GP referral letters to orthopaedic surgeons.

\section{The PT workshop}

To learn about current OA treatment recommendations, eligible PTs were encouraged to attend the PT workshop arranged in Stavanger on the 26th of October 2016. The workshop included a one-day (9h) OA educational programme organised by the "Active with osteoArthritis" (ActiveA) management programme [36], which builds on similar Swedish [41] and Danish [42] programmes. The workshop included an update on OA epidemiology, clinical features, and treatment recommendations. Education in delivery of a patient OA education programme, individually tailored semi-standardised exercises, performance testing, and healthy eating and weight reduction strategies was given. The PTs received access to the ready-to-use patient OA education programme (PowerPoint file and manuscript) and access to a database with recommendations for resistance exercises and dose specifications. As part of the ActiveA management programme, the PTs were encouraged to regularly arrange group-based $3 \mathrm{~h}$ patient $\mathrm{OA}$ education programmes followed by a 6 weeks exercise programme with twice weekly 1-h supervised group sessions (For more details, see Østerås et al. [49]).

\section{The multidisciplinary workshop}

The local project group (AP, HW, IBB and TH) arranged one multidisciplinary workshop in each of the six town districts. The separation by districts was done purposely to facilitate communication between GPs and PTs working in the neighbourhood. The second purpose of the workshop was to present current recommendations for OA treatment. The 1.5-h multidisciplinary workshop took place after work hours during November and December 2016, which was at the start of the transition period. It included an update on current treatment recommendations for OA care and a presentation of the PT-led patient OA education and exercise programme (the ActiveA programme). An orthopaedic surgeon presented views on when to consider referral to secondary care, relevant information to include in the GP referral letter, and recommendations for the use of imaging modalities for decision making about joint replacement surgery. Towards the end of the workshop, the local project group facilitated a multidisciplinary discussion regarding OA management.

\section{Development of a PT discharge report template}

Research on barriers or facilitators for writing discharge reports are lacking, but the project group hypothesized that time could be a limiting factor and that PTs' uncertainty regarding appropriate content and quantity could represent barriers. To standardize the content and potentially reduce the time needed for PTs to write discharge reports, a template for OA discharge reports was developed by the project group and distributed to the PTs. The one-paged template included the following items: patient characteristics, treatment period, pretreatment assessment (4-5 lines), treatment goal, treatment effect conclusions (3-4 lines), and post-treatment assessment (including pain level at activity/rest/night, restricted joint range of motion, muscle strength, joint stability, physical function, walking ability and walking aids, physical performance tests, OA-specific patient reported outcomes, work participation, smoking and body weight/body mass index).

\section{Data collection}

The data collection took place during two periods of 8 weeks: the pre-implementation period on September 19th -November 6th in 2016 and the post-implementation period on September 18th -November 5th in 2017.

The patient participants self-reported on an anonymous two-paged paper questionnaire handed out by the PTs after a treatment session and put it in a sealed 
envelope before leaving the clinic. The questionnaire included the following items: age, sex, OA joint location (hip/knee, uni. vs. bilateral), joint prosthesis in hip/knee (yes/no; uni. vs. bilateral), pain level (Likert scale, five levels), physical function (Likert scale, five levels) and patient-reported quality of OA care (quality indicators (QIs), 16 items).

Number of discharge reports to referring GPs was extracted from the Norwegian Health Economics Administration (Helfo), which is the Directorate of Health's external agency responsible for making payments from the National Insurance scheme to healthcare providers, suppliers and service providers, as well as individual refunds of expenses.GP referral letters were extracted from the Stavanger University Hospital's register.

\section{Primary outcome}

The primary outcome was change in patient-reported quality of OA care from pre- to post-implementation period. It was measured with the OsteoArthritis Quality Indicator questionnaire version 2 (OA-QI v2) (Additional file 1) [50]. OA-QI v1 was developed in 2010 based on published QIs for OA care identified in a literature search and was refined using expert panels and patient interviews [51]. A minor revision was undertaken in 2015 [50]. OA-QI v2 reflects current OA care guideline recommendations $[4,8-10]$ and includes 16 QI items related to patient OA education and information, regular provider assessments, referrals, and pharmacological treatment. Previous applications of the questionnaire have showed acceptable measurement properties including reliability, validity, responsiveness, and interpretability $[50,51]$. OA-QI v1 has been previously tested in UK primary care in a cluster-randomised trial and has been shown to be responsive to the use of national recommendations for OA care [43].

An example of an item with response alternatives is as follows: 'Have you been given information about osteoarthritis from a health professional? Yes/No/Don't remember'. Each QI item was considered passed if the patient had checked 'Yes' and was considered 'eligible' if the patient responded 'Yes' or 'No' for that item. On the patient level, the QI pass rate was calculated as the total number of items passed divided by the number of eligible items for each patient (in percentage), ranging from 0 to 100 , with 100 representing the best quality of care score. On the group level, the mean total pass rate was calculated.

\section{Secondary outcome measures PT discharge reports}

The number of Stavanger PTs' registered discharge reports to referring GPs was extracted from the Helfo register. The content could not be accessed, but the number of discharge reports was seen as a quality indicator given the low level of reports in traditional care.

\section{Information in GP referral letters}

Stavanger GPs' referral letters to the Department of Orthopaedic Surgery at Stavanger University Hospital during pre- and post-implementation periods were anonymized by a secretary outside the project group. Referrals related to acute conditions (e.g., ligament ruptures, infections), hip impingement conditions or post-operative review were excluded. The project group discussed and agreed beforehand on a list of 31 items that they considered relevant to be included in GP referral letters. The list was based on current guideline recommendations (e.g., that core treatment should be provided prior to surgery) and other information that the orthopaedic surgeons need for their evaluation of whether the patient is a candidate for arthroplasty. Two of these items (medication list and comorbidity) are normally automatically included in the electronic referral. Inclusion of information in the anonymized referral letters was scored (included vs. not included) by the first author.

\section{Core treatment}

The proportions of people with OA that, according to the GP referral letter, had used one or more of the core treatment modalities (physiotherapy, supervised exercise, weight reduction, OA information and/or OA education programme) prior to orthopaedic referral, were calculated.

\section{Use of imaging for $O A$ assessment}

The proportion of people that, according to the GP referral letter, had been assessed using an MRI for decision making on joint replacement surgery, but not a conventional radiograph, were calculated. Those with no use of imaging were ignored.

Deviation from the protocol (clinicaltrials.gov: NCT02876120): We were unable to assess the proportion of people with OA referred to orthopaedic surgeon in secondary care that underwent scheduled joint surgery. This was due to not being able to determine relevant patient cases within the hospital's ICT system.

\section{Statistical analyses}

The patient samples represent convenience samples. A time series-repeated observations of outcome measurements was collected during the pre- and postimplementation with the $8+8$ weeks representing 16 time points. Linear mixed models showed no slopes within the pre- or the post-implementation period. It was therefore decided to pool data for the 8 time points during the pre- and the 8 time points in the postimplementation period. A linear multi-level mixed models with random intercepts was fitted to adjust for 
the effect of clustering (PT clinic). There were 1-7 PTs working in each PT clinic. Since the intraclass correlation coefficient (ICC) was very low $(<0.001)$ and singlelevel and multi-level analyses gave similar results, a multilevel model was considered unnecessary. Hence, the primary outcome was assessed applying a singlelevel model with a before-after design to evaluate level changes from the pre-implementation period to the post-implementation period. The final regression model was adjusted for patients' age and sex. Individual OAQI v2 items were analyzed applying logistic regression crude models and the models were adjusted for patients' age and sex.

The proportions of referral letters with vs. without relevant information on each of the 31 predefined items were assessed with unadjusted logistic regression models, or with unadjusted logistic regression with the Firth procedure for bias reduction in rare events. To account for multiple analyses testing, a Bonferroni correction of the $p$-value was done $(p=0.0016)$. A randomized subsample (20\%) of the GP referral letters was re-scored by a co-author (AP), and the two sets of scores were compared. Inter-rater reliability for the two raters (NØ and AP) was examined by calculation of perfect agreement and kappa. Statistical analyses were performed using STATA/IC 14.

\section{Patient and public involvement and engagement}

Two patient research partners were involved during study planning and in development of study materials (including the questionnaire and patient information). Using the GRIPP2 reporting checklist [52], a summary of the patient and public involvement and engagement in the study is presented in the Additional file 2.

\section{Results}

In 2016, 101 GPs and 48 PTs in private practice in Stavanger were eligible for the START study. Thirty PTs in Stavanger attended the ActiveA workshop in October 2016. Another 10 PTs had previously attended an ActiveA workshop (prior to the transition period), and one PT clinic (involving 2 PTs) had started providing OA education and exercise programme to their patients prior to the transition period. Thirty-one $(65 \%)$ of the PTs and 33 (33\%) of the GPs attended the multidisciplinary workshop. In total 13 of the 15 eligible PT clinics and 22 of the 31 GP practices within Stavanger were represented at the workshop.

During the pre-implementation period, 208 patient participants were recruited from 13 PT clinics, and 125 patient participants from 11 PT clinics were recruited during the post-implementation period (Table 1). The number of patients per clinic ranged from one to 57 during pre-implementation and two to 30 during post-
Table 1 Patient characteristics in pre- and post-implementation samples

\begin{tabular}{|c|c|c|}
\hline \multirow[b]{2}{*}{ Variable } & \multicolumn{2}{|c|}{ Patient participants } \\
\hline & $\begin{array}{l}\text { pre- } \\
\text { implementation } \\
(n=208)\end{array}$ & $\begin{array}{l}\text { post- } \\
\text { implementation } \\
(n=125)\end{array}$ \\
\hline Sex, female, n (\%) & $150(72)$ & $81(65)$ \\
\hline Age, mean (SD) & $63(10)$ & $65(10)$ \\
\hline \multicolumn{3}{|c|}{ Osteoarthritis joint location, n (\%) } \\
\hline Hip/hips & $48(24)$ & $33(27)$ \\
\hline Knee/knees & $75(37)$ & $47(39)$ \\
\hline $\begin{array}{l}\text { Hip and knee and/or } \\
\text { multisite }\end{array}$ & $81(40)$ & $42(34)$ \\
\hline \multicolumn{3}{|c|}{ Hip or knee joint prosthesis, n (\%) } \\
\hline No joint prosthesis & $157(75)$ & $92(74)$ \\
\hline One joint & $35(17)$ & $25(20)$ \\
\hline Two or more joints & $16(8)$ & $8(6)$ \\
\hline \multicolumn{3}{|l|}{ Pain, n (\%) } \\
\hline No pain & $1(0.5)$ & $4(3)$ \\
\hline Very mild pain & $18(9)$ & $13(10)$ \\
\hline Mild pain & $44(21)$ & $22(18)$ \\
\hline Moderate pain & $112(54)$ & $71(57)$ \\
\hline Severe pain & $28(14)$ & $15(12)$ \\
\hline \multicolumn{3}{|l|}{ Self-reported function, n (\%) } \\
\hline Very good function & $3(1)$ & $2(2)$ \\
\hline Good function & $57(27)$ & $36(29)$ \\
\hline $\begin{array}{l}\text { Neither good nor poor } \\
\text { function }\end{array}$ & $67(32)$ & $47(38)$ \\
\hline Poor function & $70(34)$ & $32(26)$ \\
\hline Very poor function & $6(3)$ & $8(6)$ \\
\hline
\end{tabular}

implementation periods. The patient participants' mean age was 63 years at pre- and 65 years at postimplementation, and females accounted for 72 and $65 \%$ of the two samples, respectively. Patients' characteristics are provided in Table 1.

The hospital received 104 GP referral letters for assessment by an orthopaedic surgeon during the preimplementation period, 86 of these were included in this evaluation and 18 were excluded (not OA-related condition $n=7$, post-operative review $n=6$, acute condition $n=5$ ). For the post-implementation period, the hospital received 114 referral letters, of which 103 were included and 11 were excluded (acute condition $n=6$, not OArelated condition $n=2$, hip impingement $n=1$, postoperative review $n=1$, referred by hospital doctor $n=1$ ).

\section{Primary outcome}

The OA-QI v2 mean (SD) total pass rate increased from 62.4 (23.6) to 67.7 (21.2) from pre-to post-implementation period (mean difference 5.3; 95\% confidence interval (CI) 
$0.31,10.35 ; p=0.037)$ as illustrated in Fig. 3. When adjusted for patient age and sex, the difference became statistically non-significant (mean difference 4.96; 95\% CI $-0.18,10.12 ; p=0.057$ ). Figure 4 illustrates that there was no slope during any of the periods, but that there was a small level change from the pre- to post-implementation period.

Individual QI item pass rates are provided in Table 2. Figure 5 illustrates the differences in item pass rates during pre- and post-implementation periods. Eight individual item pass rates increased from pre- to postimplementation by $3-12$ percentage points, four were mainly unchanged and four showed a reduction in pass rates by $4-14$ percentage points. The pass rates increased for all five items on information: about the OA disease, treatment alternatives, self-management, importance of physical activity and on potential effects and side effects of anti-inflammatory medication. The patient participants had significantly higher odds during postimplementation for having received information on different treatment alternatives (Odds ratio (OR) 1.9; 95\% CI 1.08, 3.24; $p=0.024$ ) and on self-management (OR 2.4; $95 \%$ CI 1.33, 4.32; $p=0.003$ ) compared to during pre-implementation. Higher pass rates post- compared to pre-implementation were seen for most of items reflecting recommended core treatment, but not for the two items regarding weight management, for which the pass rate was unchanged or slightly reduced.

\section{Secondary outcomes PT discharge reports}

Both the total number of discharge reports and number of PTs writing discharge reports showed a small increase from pre- to post-implementation. The number of registered PT discharge reports was 149 (registered by 24 PTs) during the pre- and 158 (registered by 30 PTs) during the post-implementation period. The mean (minmax) discharge reports per PT was 6 (1-27) during preand $6(1-21)$ during post-implementation.

\section{Information in GP referral letters}

Overall, only minor changes in the information included in GP referral letters were observed from pre- to postimplementation period (Table 3). However, there was a clear increase in the proportion of referral letters that included information on duration of pain symptoms and smoking cessation from pre- to post-implementation (Table 3).

\section{Core treatment}

According to the GP referral letters, there was a small, but statistically non-significant, increase in the proportion of people with OA that had exploited the core treatment modalities before being referred to orthopaedic surgeon ( $31 \%$ vs. $34 \%$, OR $1.2 ; 95 \%$ CI $0.61,2.07 ; p=$ $0.706)$. The proportion of referral letters including information on prior use of physiotherapy increased from 22 to $31 \%$, but the difference in odds did not reach statistical significance (OR 1.2; 95\% CI 0.65, 2.33; $p=0.515$ ).

\section{$M R I$ and conventional radiographs for $O A$ assessment}

The proportions that had taken an MRI for OA assessment were $47 \%(n=40)$ during pre- and $49 \%(n=50)$ during post-implementation period. Among these, the proportions that had only taken MRI, and not conventional radiographs, were similar during the pre- and post-implementation periods: $63 \%(25 / 40)$ vs. $64 \%(32 /$ 50), respectively.

\section{Inter-rater reliability}

On the referral level, the inter-rater reliability was acceptable with a perfect agreement mean score of $94 \%$ (minmax: $84-100 \%)$. On the single item level, inter-rater reliability was acceptable with a perfect agreement mean score of 96\% (min-max: 68-100\%). The item 'Information on pain level included' showed the lowest agreement, since one rater scored 'Yes' and the other rater scored 'No' on six (32\%) of the 19 referral letters. For all other items, the agreement was very high. The mean kappa was 0.77 with values ranging from 0.44 to 1.00 .

\section{Discussion}

The START study showed that after implementing international guidelines for OA care among PTs and GPs in primary healthcare, OA management indicated a non-significant, small shift towards improved alignment with international recommendations. The improvement was mainly related to core treatment modalities and was in particular evident for provision of information on OA treatment alternatives and on self-management. This was supported by a small, statistically non-significant increase in the proportion of GP referral letters to orthopaedic surgeons indicating that core treatment modalities had been previously used. However, patientreported receipt of advice about weight management did not improve, and there were negligible to no changes related to PT discharge reports, information in GP referral letters, and the use of different imaging modalities for OA assessment.

The patient sample characteristics in this and previous studies [31, 48-51, 53-55] were comparable on age, sex and OA location, but the START study included a higher proportion of patient participants with joint prosthesis as compared with a previous implementation study [49]). The mean total pass rate for the preimplementation period in the START study was much higher compared to other studies that have used the OA-QI questionnaire [31, 48-51, 53-55]. The high pre- 


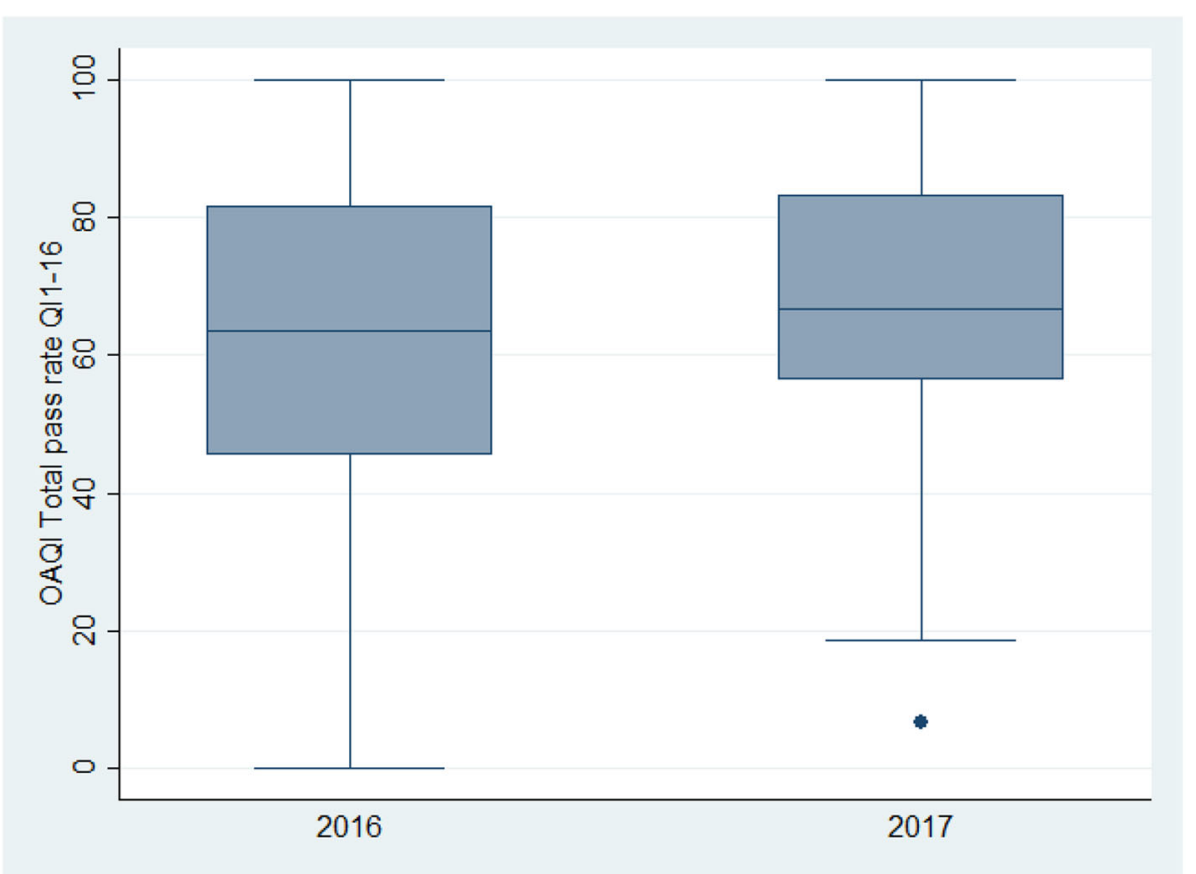

Fig. 3 Patient-reported quality of osteoarthritis care. Boxplot of total mean score during the pre-implementation in 2016 ( $n=208$ patient responders) and the post-implementation in 2017 ( $n=125$ patient responders)

implementation score in the START study may be related to differences in patient recruitment since this study recruited patient participants that had received 46 physiotherapy treatment sessions. This in contrast to the previous studies, in which patients were recruited from the general population [51, 55], GP practices [49, 53], at first session of physiotherapy [49], scheduled for a consultation with an orthopaedic surgeon [31], or among members of a patient organisation [54, 55]. In addition, 10 physiotherapists in this study had attended an ActiveA workshop prior to the transition phase, and 1 clinic had started providing OA education and exercise programme to their patients. This may also potentially have contributed to the high pre-implementation pass rate in the START study.

The 5 percentage points increase in mean total pass rate from the pre- to post-implementation period in the START study indicates that the provided care became somewhat more in line with the guideline recommendations. This finding was supported by the small increase

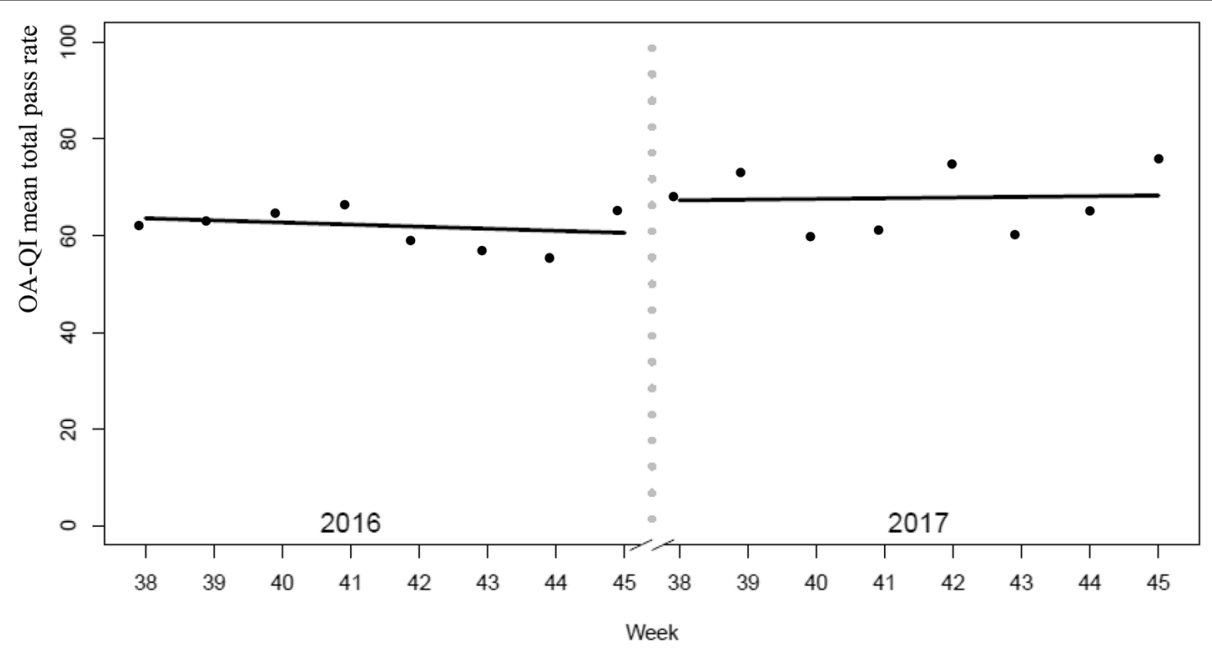

Fig. 4 Patient-reported quality of osteoarthritis care. Marginsplot of total mean score during 8 pre-implementation weeks in 2016 ( $n=208$ patient responders) and 8 post-implementation weeks in 2017 ( $n=125$ patient responders) 
Table 2 Patient-reported quality of osteoarthritis care: individual item pass rates and odds ratio for item achievement

\begin{tabular}{|c|c|c|c|c|c|c|c|}
\hline \multirow[t]{2}{*}{ Individual QI items } & \multicolumn{3}{|c|}{ Individual item pass rates ${ }^{a}$} & \multicolumn{4}{|c|}{ OR $(95 \% \mathrm{Cl})$ for item achievement } \\
\hline & Pre-implemen-tation & $\begin{array}{l}\text { Post-implemen- } \\
\text { tation }\end{array}$ & $\begin{array}{l}\Delta \text { Post }- \\
\text { Pre pass rates }\end{array}$ & $\begin{array}{l}\text { Crude } \\
\text { model }\end{array}$ & $\begin{array}{l}p- \\
\text { value }\end{array}$ & $\begin{array}{l}\text { Adjusted } \\
\text { model }^{\mathrm{b}}\end{array}$ & $\begin{array}{l}p \text { - } \\
\text { value }\end{array}$ \\
\hline $\begin{array}{l}\text { Information about OA from a HP } \\
\left(n=308^{\circ}\right)\end{array}$ & 84 & 89 & $\uparrow 5$ & $1.7(0.83,3.40)$ & 0.152 & $1.8(0.86,3.60)$ & 0.124 \\
\hline $\begin{array}{l}\text { Information about different } \\
\text { treatment alternatives }(n=308)\end{array}$ & 67 & 79 & $\uparrow 12$ & $1.9(1.08,3.24)$ & 0.024 & $1.8(1.04,3.14)$ & 0.037 \\
\hline $\begin{array}{l}\text { Information on self-management } \\
(n=308)\end{array}$ & 69 & 84 & $\uparrow 15$ & $2.4(1.33,4.32)$ & 0.003 & $2.6(1.43,4.79)$ & 0.002 \\
\hline $\begin{array}{l}\text { Information about importance of } \\
\text { physical activity }(n=328)\end{array}$ & 91 & 96 & $\uparrow 5$ & $2.2(0.81,6.19)$ & 0.120 & $2.3(0.83,6.47)$ & 0.108 \\
\hline $\begin{array}{l}\text { Referred to HP for physical } \\
\text { ctivity/exercise }(n=316)\end{array}$ & 87 & 90 & $\uparrow 3$ & $1.4(0.68,2.93)$ & 0.344 & $1.4(0.66,2.86)$ & 0.406 \\
\hline Advised to lose weight $(n=158)$ & 49 & 45 & $\downarrow 4$ & $0.9(0.44,1.66)$ & 0.649 & $0.8(0.43,1.65)$ & 0.618 \\
\hline $\begin{array}{l}\text { Referred for support to lose } \\
\text { weight }(n=163)\end{array}$ & 12 & 14 & $\downarrow 2$ & $1.2(0.45,3.31)$ & 0.680 & $1.0(0.33,2.87)$ & 0.966 \\
\hline $\begin{array}{l}\text { Assessed for functional ability } \\
(n=186)\end{array}$ & 33 & 35 & $\uparrow 2$ & $1.1(0.57,2.01)$ & 0.835 & $1.1(0.56,2.06)$ & 0.823 \\
\hline $\begin{array}{l}\text { Assessed the need for walking aids } \\
(n=168)\end{array}$ & 36 & 22 & $\downarrow 14$ & $0.5(0.24,1.01)$ & 0.055 & $0.5(0.25,1.10)$ & 0.089 \\
\hline $\begin{array}{l}\text { Assessed the need for other aids } \\
(n=151)\end{array}$ & 13 & 4 & $\downarrow 9$ & $0.3(0.06,1.30)$ & 0.105 & $0.3(0.06,1.32)$ & 0.109 \\
\hline Joint pain assessed by HP $(n=309)$ & 79 & 80 & $\uparrow 1$ & $1.1(0.61,1.91)$ & 0.804 & $1.1(0.62,1.97)$ & 0.746 \\
\hline $\begin{array}{l}\text { Paracetamol recommended as } \\
\text { first line }(n=303)\end{array}$ & 72 & 67 & $\downarrow 5$ & $0.8(0.49,1.34)$ & 0.415 & $0.9(0.53,1.48)$ & 0.639 \\
\hline Offered stronger pain killers $(n=213)$ & 47 & 55 & $\uparrow 8$ & $1.4(0.78,2.42)$ & 0.271 & $1.3(0.75,2.38)$ & 0.319 \\
\hline $\begin{array}{l}\text { Information about anti-inflammatory } \\
\text { medication }(n=206)\end{array}$ & 62 & 68 & $\uparrow 6$ & $1.4(0.74,2.47)$ & 0.321 & $1.3(0.70,2.37)$ & 0.412 \\
\hline Offered steroid injection $(n=206)$ & 24 & 23 & $\downarrow 4$ & $1.0(0.50,1.87)$ & 0.915 & $0.9(0.47,1.83)$ & 0.837 \\
\hline $\begin{array}{l}\text { Referred to orthopaedic surgeon } \\
(n=208)\end{array}$ & 51 & 54 & $\uparrow 3$ & $1.1(0.64,2.02)$ & 0.648 & $1.1(0.64,2.04)$ & 0.658 \\
\hline
\end{tabular}

HP Healthcare professional, OA Osteoarthritis, OR Odds ratio, QI Quality indicator

${ }^{a}$ Individual item pass rates were calculated as the proportion of patients reporting that the QI was passed ('Yes') divided by the proportion of patients who were eligible ('Yes' or 'No') for that Ql item (in percentage). Pass rates range from 0 to 100, with 100 representing that all eligible patients reported pass ('Yes') for that QI item

${ }^{\mathrm{b}}$ Logistic regression model adjusted for patients' sex and age

' Number of eligible patients for the Ql item, i.e., patients that have responded 'Yes' or 'No' to that item. Patient responses 'Not applicable' are ignored

in the proportion of GP referral letters indicating that core treatment had been exploited before surgical treatment options were considered. In the SAMBA study, a similar OA guideline implementation study, the mean total pass rate in the intervention group increased from $39 \%$ at baseline to $60 \%$ at the six-month follow-up [49]. Hence, the pre-implementation pass rate in the START study (62\%) was higher than the post-implementation pass rate in the SAMBA study, which leaves a smaller scope of improvement in the START study. While the 5 -point increase was higher than the previously reported measurement error of 3 for this instrument [50], the importance of a 5-point increase on the OA-QI questionnaire may be debated.

For individual OA-QI items post-implementation pass rates of $79-96 \%$ were seen for most core treatment items. These pass rates are comparable to the post- implementation rates for the intervention group in the SAMBA study [49] but are much higher than the pass rates in the observational studies [31, 48, 50, 51, 53-55]. This demonstrates the potential of judicious implementation studies in making OA management more in line with international treatment recommendations. However, the post-implementation pass rates for weight loss advice and for referrals to support for losing weight remained low in the START study as in the SAMBA study [49]. Also, observational studies have revealed low pass rates for weight management uncovering a large scope for improvement $[31,51,53-55]$. The low pass rates may be related to health professionals' barriers towards discussing weight issues and their prioritizing to review other aspects of health $[32,33,35]$. Further, there are relatively few weight loss services in Norway that the GP can refer to, and the GPs may not be aware of those. 


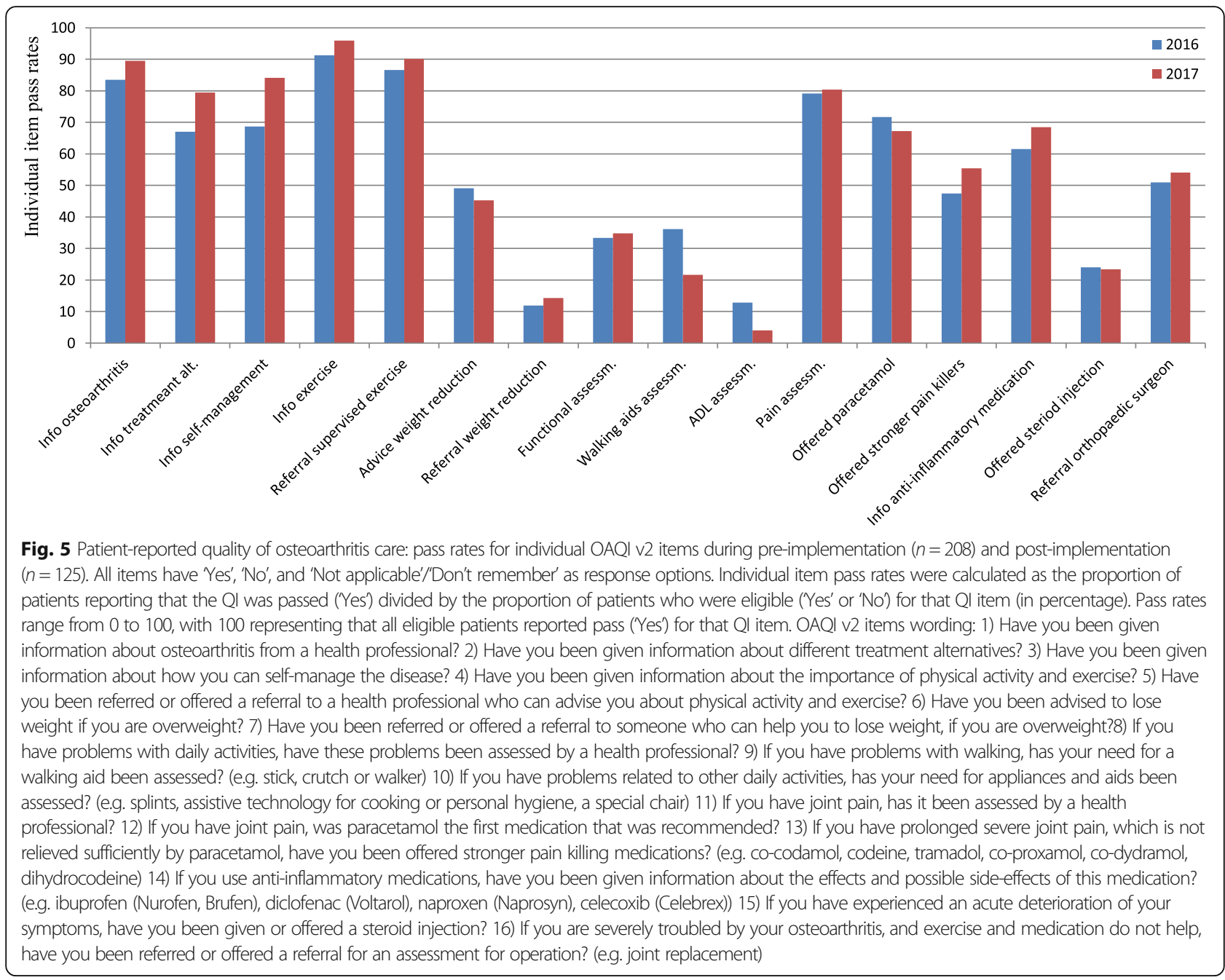

In a previous study, a large proportion of PTs reported that they would address weight by the provision of advice, but some lacked confidence in addressing weight loss [33]. While PTs believe they have a role in addressing weight loss, they felt inadequately equipped to integrate weight loss in their management approach [56]. Since weight reduction has been shown to significantly reduce symptoms and improve function among those with overweight $[57,58]$, future studies should investigate how weight loss management for people with OA can be improved.

To our knowledge, only one small previous study has assessed Norwegians PTs' practice of writing discharge reports [37]. As PT discharge reports may provide important information for the GP to review together with the patient, the discharge report may represent an element in the continuity of patient information transfer. Information from the PT to the GP on the effect of core treatment and the patients' status may lead to more appropriate referrals for candidates for joint replacement and reduce the number of inappropriate referrals. In this study, the results showed only a small increase in the total number of registered discharge reports and in the number of PTs writing one or more discharge reports. While this study was a first attempt to make interprofessional communication a standard practice, ensuring the quality of the reports should be the next step in a future study. The results also revealed a large inter-provider variation with the number of discharge reports registered per PT ranging from none to more than 20 . Hence, there may be other unknown barriers that hinder the PTs in writing discharge reports. It was out of the scope of this study to investigate other barriers or facilitators for writing discharge reports.

A previous study found that the content of GP referral letters to orthopaedic surgeons often was suboptimal [59]. This finding is supported in more recent studies on referral letters in other medical disciplines showing that basic items necessary for appropriate triage often were lacking [60, 61]. According to a Cochrane Review [62], active, local educational interventions including secondary care specialists are shown to impact referral practice, 
Table 3 Information in GPs' referral letters of patients to orthopaedic surgeon during pre- and post-implementation

\begin{tabular}{|c|c|c|c|c|}
\hline \multirow[b]{2}{*}{$\begin{array}{l}\text { Items considered relevant to be included } \\
\text { in GPs' referral letters: } \\
\text { Information on ... }\end{array}$} & \multicolumn{2}{|c|}{$\begin{array}{l}\% \text { referrals that included } \\
\text { this information during }\end{array}$} & \multirow[b]{2}{*}{$\begin{array}{l}\text { OR }(95 \% \mathrm{Cl}) \text { for reporting this } \\
\text { information }\end{array}$} & \multirow[b]{2}{*}{$\begin{array}{l}p- \\
\text { value }^{\mathrm{a}}\end{array}$} \\
\hline & $\begin{array}{l}\text { pre- } \\
\text { implementation } \\
(n=86)\end{array}$ & $\begin{array}{l}\text { post- } \\
\text { implementation } \\
(n=103)\end{array}$ & & \\
\hline Results from a clinical examination & 45 & 51 & $1.2(0.69,2.18)$ & 0.482 \\
\hline Restricted joint range of motion & 35 & 30 & $0.8(0.43,1.48)$ & 0.484 \\
\hline Joint malalignment & 7 & 11 & $1.6(0.56,4.51)$ & 0.379 \\
\hline Reduced joint stability & 9 & 12 & $1.3(0.50,3.31)$ & 0.602 \\
\hline Skin conditions, if relevant for potential surgery ${ }^{b}$ & 0 & 3 & $6.0(0.31,118.3)$ & 0.111 \\
\hline Affection of walking ability & 64 & 53 & $0.6(0.35,1.12)$ & 0.111 \\
\hline Eventual use of walking aids ${ }^{b}$ & 6 & 6 & $1.0(0.31,3.19)$ & 0.997 \\
\hline The activity level & 55 & 53 & $1.0(0.54,1.69)$ & 0.863 \\
\hline Health related quality of life & 10 & 8 & $0.7(0.27,1.96)$ & 0.519 \\
\hline The pain level & 92 & 80 & $0.3(0.11,0.76)$ & 0.012 \\
\hline The duration of pain symptoms & 53 & 81 & $3.6(1.89,6.89)$ & $<0.001$ \\
\hline Eventual progression of pain & 51 & 70 & $2.2(1.22,4.03)$ & 0.009 \\
\hline Night pain & 44 & 46 & $1.0(0.60,1.89)$ & 0.842 \\
\hline Conventional radiograph (CR) being taken & 57 & 57 & $1.0(0.57,1.81)$ & 0.966 \\
\hline Magnetic resonance image (MRI) being taken & 47 & 49 & $1.1(0.61,1.93)$ & 0.781 \\
\hline The $C R$ and MRI image(s) being recent ${ }^{c}$ & 84 & 84 & $1.0(0.45,2.13)$ & 0.967 \\
\hline Used physiotherapy & 22 & 31 & $1.2(0.65,2.33)$ & 0.515 \\
\hline Used supervised exercise & 14 & 21 & $1.7(0.77,3.62)$ & 0.190 \\
\hline $\begin{array}{l}\text { Having received information on the } O A \text { disease and } \\
\text { treatment alternatives }{ }^{b}\end{array}$ & 2 & 4 & $1.5(0.32,7.37)$ & 0.597 \\
\hline Having participated in an OA education programme ${ }^{b}$ & 1 & 4 & $2.6(0.40,16.7)$ & 0.321 \\
\hline Paracetamol use & 41 & 45 & $1.2(0.66,2.10)$ & 0.584 \\
\hline NSAID use & 62 & 56 & $0.8(0.45,1,44)$ & 0.460 \\
\hline Topical NSAID use ${ }^{b}$ & 5 & 2 & $0.5(0.09,2.18)$ & 0.322 \\
\hline Opioid use & 35 & 27 & $0.7(0.34,1.30)$ & 0.253 \\
\hline $\begin{array}{l}\text { Used non-surgical treatment alternatives for three to six } \\
\text { months }\end{array}$ & 13 & 15 & $1.2(0.50,2.68)$ & 0.725 \\
\hline Overweight or body mass index & 12 & 9 & $0.7(0.28,1.88)$ & 0.512 \\
\hline Having tried weight reduction, if relevant ${ }^{b}$ & 6 & 1 & $0.2(0.03,1.35)$ & 0.101 \\
\hline Smoking status & 22 & 7 & $0.3(0.12,0.72)$ & 0.007 \\
\hline Having tried to stop smoking, if relevant ${ }^{b}$ & 7 & 2 & $0.1(0.03,0.41)$ & 0.001 \\
\hline Comorbidity & 86 & 76 & $0.5(0.24,1.08)$ & 0.078 \\
\hline Current medications & 91 & 86 & $0.7(0.26,1.64$ & 0.362 \\
\hline
\end{tabular}

HP Health professional, NSAIDS Non-Steroidal Antiinflammatory Drugs, OA Osteoarthritis, OA-QI v2 OsteoArthritis Quality Indicator questionnaire version 2, QI Quality indicator

${ }^{a}$ To account for multiple analyses testing, a Bonferroni correction of the $\mathrm{p}$-value was done $(p=0.0016)$

${ }^{b}$ Analyzed using logistic regression with the Firth procedure for bias reduction in rare events

c Recent was defined as within the past 12 months

but this was not seen in the START study as there were very few changes in the content of referral letters or in the use of imaging modalities for OA assessment. The multidisciplinary workshop in the START study lasted only $1.5 \mathrm{~h}$, and the information and discussion on information in referral letters and the recommendations for imaging may have fallen behind the other topics covered. A more intense focus in the workshop or provision of a checklist for recommended content may have improved the content of GPs' referral letters. 
Although a large proportion of the GP referral letters contained information on pain, only $8 \%$ included information on whether the patients' quality of life was affected and barely half included information from a medical examination. Only a small proportion provided information on whether core and supplementary treatment options (e.g. medication) had already been tried. According to the NICE guideline [4], referrals for consideration of joint surgery should be restricted to people, in which joint symptoms have a substantial impact on their quality of life and the symptoms are refractory to non-surgical treatment. The results in this study indicate a large scope for improving the content of the referral letters to facilitate timely access to orthopaedic surgeons for consideration of joint replacement specialty care.

One strength of the START study was its alignment to the "Joint Implementation of Guidelines for oSteoArthritis in Western Europe" (JIGSAW-E) (https:// jigsaw-e.com/) which was based upon the MOSAICS study [47] where implementation science and knowledge mobilisation theory (e.g. Normalisation Process Theory, implementation theory, the Theoretical Domains Framework and principles of adult learning) was used to guide implementation and intervention design. Another strength of this study is the use of opinion leaders/clinical champions as moderators in the multidisciplinary workshops and facilitators for the implementation of $\mathrm{OA}$ guidelines. The involvement of both primary and secondary healthcare services in this study emphasized the importance of continuity of patient care. The multidisciplinary workshops mobilized a large proportion of GPs and PTs in the Stavanger Municipality to become updated on OA management. The active involvement of patient research partners in the planning phase ensured relevant patient information and survey questions as well as advices regarding the data collection and patient confidentiality.

Some methodological limitations should be taken into consideration when interpreting the results of the present study. In light of recent research on sample size and power with an interrupted time series design [63], the small patient sample size in the START study indicates that the power may have been low. The long transition period means that only persistent effects were captured and that the effect of the intervention may have been underestimated. Further, that 2 PTs already were providing $\mathrm{OA}$ education and exercise in line with the ActiveA management programme during preimplementation period, may have reduced the effect of the implementation in the START study. It may also be a limitation that we were unable to adjust for PT clustering of patients because the patient reports were anonymous. However, as the intervention was designed to standardize PTs' approach and the ICC for the PT clinic level was very low, we do not expect a high variation between individual PTs' approach in this study. That two PT clinics did not recruit patients post-implementation may be due to reduced engagement. When excluding patient responses from these two clinics in a sensitivity analysis, the CIs became slightly more narrow, but this did not change the conclusions. Whilst this is a pragmatic implementation study the pre-implementation patient participant number did drop notably to the postimplementation, which may reflect reduced engagement among the PTs, but a selection bias related to PTs' in handing out the questionnaires cannot be ruled out. Since the number of eligible OA patients is unknown, we cannot calculate a response rate, and a patient selection bias cannot be ruled out. This also has consequences for the external validity. It is also a limitation that the registered PT discharge reports may have been related to patients with other diagnoses than OA. Since the GP referral letters were anonymized, it was not possible to distinguish between the referral letters from GPs that had attended the workshop versus from GPs that did not attend. Given that only 33\% of the GPs attended the workshop, the impact of the workshop on all referral letters generated in the locality may have been diluted. To get very significant clinical outcomes, a huge and lengthy study would be required. A mixed methods approach may have provided more in-depth understanding, but the funding available did not permit the addition of a mixed methods quantitate and qualitative agenda. However, we believe this study adds important knowledge about where the gaps currently exist.

One clinical implication of this study is that a relatively small intervention can slightly shift clinicians' provision of OA care to better align with guideline recommendations for the provision of patient information and recommending core $\mathrm{OA}$ treatment modalities. $\mathrm{Fu}$ ture studies may need to be larger, include more multifaceted and targeted interventions, and also other outcome measurements, including qualitative process evaluations, in order to see effects related to other aspects of OA care (e.g. weight reduction advising, healthy lifestyle changes, changes in the written communication between health professionals, and in the use of imaging modalities for assessment of OA). In addition, future studies should explore how to widen health professionals' engagement and to ensure persistence of behaviour change for health professionals as well as patients.

\section{Conclusions}

Implementing international OA treatment recommendations in a primary healthcare setting is a grand endeavour, which normally requires multidimensional interventions. In this study implementing OA treatment recommendations in a 
primary healthcare setting through two inter-active workshops and implementation of a discharge report template, OA management showed small, non-significant changes towards better alignment with best practice treatment recommendations.

\section{Supplementary Information}

The online version contains supplementary material available at https://doi. org/10.1186/s12891-021-03959-6.

Additional file 1. OsteoArthritis Quality Indicator questionnaire version 2 (OA-Q| v2).

Additional file 2. GRIPP2-SF checklist.

\section{Abbreviations}

Cl: Confidence interval; HELFO: Norwegian Health Economics Administration; OA: Osteoarthritis; GP: General practitioner; MRI: Magnetic resonance imaging; OR: Odds ratio; PT: Physiotherapist

\section{Acknowledgements}

We thank all the clinicians, patient participants and patient research partners that contributed to the study.

\section{Authors' contributions}

$\mathrm{NO}, \mathrm{IBB}, \mathrm{TH}$ and AP have made substantial contributions to conception, design, and conductance of the study. NO, IBB, TH, AP, EC, JQ, KD and SB have been involved in analyses and interpretation of results, drafting of the manuscript and have given final approval of the version to be published.

\section{Funding}

START and JIGSAW-E was funded by EIT-Health and the West Midlands Academic Science Network, UK, and local funding at Diakonhjemmet Hospital. IBB was funded by financial support from The Norwegian Fund for PostGraduate Training in Physiotherapy through the FYSIOPRIM project and by Stavanger Municipality. KD was part funded by a National Institute for Health Research (NIHR) Knowledge Mobilisation Research Fellowship (KMRF-201403-002) and is an NIHR Senior Investigator. JQ is part funded by a NIHR Clinical Research Network West Midlands, Research Scholar Fellowship. The views expressed are those of the author(s) and not necessarily those of the NIHR or the Department of Health and Social Care.

\section{Availability of data and materials}

The datasets used and/or analysed during the current study are available from the corresponding author on reasonable request.

\section{Ethics approval and consent to participate}

The Regional Committee for Medical and Health Research Ethics (Ref. no.: 2016/1734 REK South-East D) and The Data Inspectorate/ Data Protection Official at Stavanger University Hospital (Ref. no.: 2016/31) approved the study. The patient participants indirectly consented to participate by completing the anonymous questionnaire.

\section{Consent for publication}

Ethical consent was given for the publication of anonymous data.

\section{Competing interests}

Not applicable.

\section{Author details}

${ }^{1}$ Division of Rheumatology and Research, National Advisory Unit on Rehabilitation in Rheumatology, Diakonhjemmet Hospital, Oslo, Norway ${ }^{2}$ Hillevåg Fysioterapi og Trening, Stavanger, Norway. ${ }^{3}$ Legesenteret Mariero, Stavanger, Norway. ${ }^{4}$ Impact Accelerator Unit, Versus Arthritis Primary Care Centre, Keele University, Staffordshire ST5 5BG, UK. ${ }^{5}$ Department of Orthopaedics, Division of Surgery, Stavanger University Hospital, Stavanger, Norway. ${ }^{6}$ Department of Public Health, The Faculty of Health Sciences, University of Stavanger, Stavanger, Norway.
Received: 21 September 2020 Accepted: 5 January 2021

Published online: 14 January 2021

\section{References}

1. Murphy L, Schwartz TA, Helmick CG, Renner JB, Tudor G, Koch G, et al, Lifetime risk of symptomatic knee osteoarthritis. Arthritis Rheum. 2008;59: 1207-13.

2. Murphy LB, Helmick CG, Schwartz TA, Renner JB, Tudor G, Koch GG, et al. One in four people may develop symptomatic hip osteoarthritis in his or her lifetime. Osteoarthritis Cartilage. 2010;18:1372-9.

3. Bijlsma JW, Berenbaum F, Lafeber FP. Osteoarthritis: an update with relevance for clinical practice. Lancet. 2011;377:2115-26.

4. National Institute for Health \& Care Excellence (NICE). Osteoarthritis: Care and management in adults. Clinical guideline (CG177). London: NICE; 2014.

5. Vos T, Flaxman AD, Naghavi M, Lozano R, Michaud C, Ezzati M, et al. Years lived with disability (YLDs) for 1160 sequelae of 289 diseases and injuries 1990-2010: a systematic analysis for the global burden of disease study 2010. Lancet. 2013;380:2163-96.

6. Bitton R. The economic burden of osteoarthritis. Am J Manag Care. 2009;15: S230-S5.

7. Ackerman IN, Pratt C, Gorelik A, Liew D. Projected Burden of Osteoarthritis and Rheumatoid Arthritis in Australia: A Population-Level Analysis. Arthritis Care Res (Hoboken). 2018;70:877-83.

8. Fernandes L, Hagen KB, Bijlsma JW, Andreassen O, Christensen P, Conaghan $P G$, et al. EULAR recommendations for the non-pharmacological core management of hip and knee osteoarthritis. Ann Rheum Dis. 2013:72:1125-35.

9. Bannuru RR, Osani MC, Vaysbrot EE, Arden NK, Bennell K, Bierma-Zeinstra SMA, et al. OARSI guidelines for the non-surgical management of knee, hip, and polyarticular osteoarthritis. Osteoarthritis Cartilage. 2019;27(11):1578-89.

10. Kolasinski SL, Neogi T, Hochberg MC, Oatis C, Guyatt G, Block J, et al. 2019 American College of Rheumatology/Arthritis Foundation guideline for the Management of Osteoarthritis of the hand, hip, and knee. Arthritis Care Res (Hoboken). 2020;72:149-62

11. Learmonth ID, Young $C$, Rorabeck $C$. The operation of the century: total hip replacement. Lancet. 2007:370:1508-19.

12. Daigle ME, Weinstein AM, Katz JN, Losina E. The cost-effectiveness of total joint arthroplasty: a systematic review of published literature. Best Pract Res Clin Rheumatol. 2012;26:649-58.

13. Dakin H, Gray A, Fitzpatrick R, Maclennan G, Murray D, Group KATT. Rationing of total knee replacement: a cost-effectiveness analysis on a large trial data set. BMJ Open. 2012;2:e000332.

14. Gademan MG, Hofstede SN, Vliet Vlieland TP, Nelissen RG, Marang-van de Mheen PJ. Indication criteria for total hip or knee arthroplasty in osteoarthritis: a state-of-the-science overview. BMC Musculoskelet Disord. 2016;17:463.

15. Bohl DD, Ondeck NT, Basques BA, Levine BR, Grauer JN. What is the timing of general health adverse events that occur after Total joint Arthroplasty? Clin Orthop Relat Res. 2017:475:2952-9.

16. Kärrholm JR, Naucler E, Vinblad J, Mohaddes M, Rolfson O. Swedish Hip Register. Annual report 2018 [Svenska Höftprotesregistret. Årsrapport 2018]; 2018

17. Paulsen A. Patient reported outcomes in hip arthroplasty registries. Dan Med J. 2014;61:B4845.

18. Swedish Knee Arthroplasty Register. Annual report 2018 [Årsrapport 2018] Lund: Lund University; 2019.

19. Judge A, Cooper C, Williams S, Dreinhoefer K, Dieppe P. Patient-reported outcomes one year after primary hip replacement in a European Collaborative Cohort. Arthritis Care Res (Hoboken). 2010;62:480-8.

20. Beswick AD, Wylde V, Gooberman-Hill R, Blom A, Dieppe P. What proportion of patients report long-term pain after total hip or knee replacement for osteoarthritis? A systematic review of prospective studies in unselected patients. BMJ Open. 2012;2:e000435.

21. Ghomrawi HM, Schackman BR, Mushlin Al. Appropriateness criteria and elective procedures--total joint arthroplasty. N Engl J Med. 2012;367:2467-9.

22. Quintana JM, Arostegui I, Escobar A, Azkarate J, Goenaga JI, Lafuente I. Prevalence of knee and hip osteoarthritis and the appropriateness of joint replacement in an older population. Arch Intern Med. 2008;168:1576-84.

23. Sherman SL, Gulbrandsen TR, Lewis HA, Gregory MH, Capito NM, Gray AD, et al. Overuse of magnetic resonance imaging in the diagnosis and treatment of moderate to severe osteoarthritis. lowa Orthop J. 2018;38:33-7. 
24. Sakellariou G, Conaghan PG, Zhang W, Bijlsma JWJ, Boyesen P, D'Agostino $M A$, et al. EULAR recommendations for the use of imaging in the clinical management of peripheral joint osteoarthritis. Ann Rheum Dis. 2017;76: 1484-94.

25. Basedow M, Esterman A. Assessing appropriateness of osteoarthritis care using quality indicators: a systematic review. J Eval Clin Pract. 2015;21:782-9.

26. Hagen KB, Smedslund G, Osteras N, Jamtvedt G. Quality of CommunityBased Osteoarthritis Care: A Systematic Review and Meta-Analysis. Arthritis Care Res (Hoboken). 2016;68:1443-52.

27. Healey EL, Afolabi EK, Lewis M, Edwards JJ, Jordan KP, Finney A, et al. Uptake of the NICE osteoarthritis guidelines in primary care: a survey of older adults with joint pain. BMC Musculoskelet Disord. 2018;19:295.

28. Jamtvedt G, Dahm KT, Holm I, Flottorp S. Measuring physiotherapy performance in patients with osteoarthritis of the knee: a prospective study. BMC Health Serv Res. 2008;8:145

29. Holden MA, Bennell KL, Whittle R, Chesterton L, Foster NE, Halliday NA, et al. How do physical therapists in the United Kingdom manage patients with hip osteoarthritis? Results of a cross-sectional survey. Phys Ther. 2018;98: 461-70.

30. Zadro J, O'Keeffe M, Maher C. Do physical therapists follow evidence-based guidelines when managing musculoskeletal conditions? Systematic review. BMJ Open. 2019;9:e032329.

31. Ingelsrud LH, Roos EM, Gromov K, Jensen SS, Troelsen A. Patients report inferior quality of care for knee osteoarthritis prior to assessment for knee replacement surgery - a cross-sectional study of 517 patients in Denmark. Acta Orthop. 2020;91:82-7.

32. Finset A. One size does not fit all: how to talk to patients about obesity. PatientEducCouns. 2009;76:147-8.

33. Holden MA, Waterfield J, Whittle R, Bennell K, Quicke JG, Chesterton L, et al. How do UK physiotherapists address weight loss among individuals with hip osteoarthritis? A mixed-methods study. Musculoskeletal Care. 2019;17: 133-44

34. Quicke JG, Holden MA, Bennell KL, Allison K. Where to from Here? Is there a role for physical therapists in enacting evidence-based guidelines for weight loss in adults with osteoarthritis who are overweight? Phys Ther. 2020;100:3-7.

35. Clarson LE, Nicholl Bl, Bishop A, Edwards JJ, Daniel R, Mallen CD. Monitoring osteoarthritis: a cross-sectional survey in general practice. Clin Med Insights Arthritis Musculoskelet Disord. 2013;6:85-91.

36. Cottrell E, Foster NE, Porcheret M, Rathod T, Roddy E. GPs' attitudes, beliefs and behaviours regarding exercise for chronic knee pain: a questionnaire survey. BMJ Open. 2017;7:e014999.

37. Gronhaug G. Physiotherapy in knee osteoarthritis: an observationell study of discharge reports [in Norwegian: Fysioterapi ved kneartrose: en observasjonell studie av epikriser]. Fysioterapeuten. 2014.

38. Allen KD, Oddone EZ, Coffman CJ, Datta SK, Juntilla KA, Lindquist JH, et al. Telephone-based self-management of osteoarthritis: a randomized trial. Ann Intern Med. 2010;153:570-9.

39. Smink AJ, Dekker J, Vliet Vlieland TP, Swierstra BA, Kortland JH, Bijlsma JW, et al. Health care use of patients with osteoarthritis of the hip or knee after implementation of a stepped-care strategy: an observational study. Arthritis Care Res (Hoboken). 2014;66:817-27.

40. Smink AJ, Bierma-Zeinstra SM, Schers HJ, Swierstra BA, Kortland JH, Bijlsma $J W$, et al. Non-surgical care in patients with hip or knee osteoarthritis is modestly consistent with a stepped care strategy after its implementation. Int J Qual Health Care. 2014;26:490-8.

41. Thorstensson CA, Garellick G, Rystedt H, Dahlberg LE. Better Management of Patients with osteoarthritis: development and Nationwide implementation of an evidence-based supported osteoarthritis self-management Programme. Musculoskeletal Care. 2015;13:67-75.

42. Skou ST, Roos EM. Good life with osteoArthritis in Denmark (GLA:D): evidence-based education and supervised neuromuscular exercise delivered by certified physiotherapists nationwide. BMC Musculoskelet Disord. 2017; $18: 72$

43. Dziedzic KS, Healey EL, Porcheret M, Afolabi EK, Lewis M, Morden A, et al. Implementing core NICE guidelines for osteoarthritis in primary care with a model consultation (MOSAICS): a cluster randomised controlled trial. Osteoarthr Cartil. 2018;26:43-53.

44. Allen KD, Oddone EZ, Coffman CJ, Jeffreys AS, Bosworth HB, Chatterjee R, et al. Patient, provider, and combined interventions for managing osteoarthritis in primary care: a cluster randomized trial. Ann Intern Med. 2017;166:401-11.

45. Penfold RB, Zhang F. Use of interrupted time series analysis in evaluating health care quality improvements. Acad Pediatr. 2013;13:S38-44.

46. Des Jarlais DC, Lyles C, Crepaz N, Group T. Improving the reporting quality of nonrandomized evaluations of behavioral and public health interventions: the TREND statement. Am J Public Health. 2004;94:361-6.

47. Dziedzic KS, Healey EL, Porcheret M, Ong BN, Main CJ, Jordan KP, et al. Implementing the NICE osteoarthritis guidelines: a mixed methods study and cluster randomised trial of a model osteoarthritis consultation in primary care--the management of OsteoArthritis in consultations (MOSAICS) study protocol. Implement Sci. 2014;9:95.

48. Osteras N, Jordan KP, Clausen B, Cordeiro C, Dziedzic K, Edwards J, et al. Self-reported quality care for knee osteoarthritis: comparisons across Denmark, Norway. Portugal and the UK RMD Open. 2015;1:e000136.

49. Osteras N, Moseng T, Bodegom-Vos LV, Dziedzic K, Mdala I, Natvig B, et al. Implementing a structured model for osteoarthritis care in primary healthcare: a stepped-wedge cluster-randomised trial. PLoS Med. 2019;16: e1002949.

50. Osteras N, Tveter AT, Garratt AM, Svinoy OE, Kjeken I, Natvig B, et al. Measurement properties for the revised patient-reported OsteoArthritis quality Indicator questionnaire. Osteoarthr Cartil. 2018;26:1300-10.

51. Osteras N, Garratt A, Grotle M, Natvig B, Kjeken I, Kvien TK, et al. Patientreported quality of care for osteoarthritis: development and testing of the osteoarthritis quality indicator questionnaire. Arthritis Care Res (Hoboken). 2013;65:1043-51.

52. Staniszewska S, Brett J, Simera I, Seers K, Mockford C, Goodlad S, et al. GRIP P2 reporting checklists: tools to improve reporting of patient and public involvement in research. BMJ. 2017;358:j3453.

53. Gronhaug G, Osteras N, Hagen KB. Quality of hip and knee osteoarthritis management in primary health care in a Norwegian county: a crosssectional survey. BMC Health Serv Res. 2014;14:598.

54. Gronhaug G, Hagfors J, Borch I, Osteras N, Hagen KB. Perceived quality of health care services among people with osteoarthritis - results from a nationwide survey. Patient Prefer Adherence. 2015;9:1255-61.

55. Larmer PJB, K.; Baldwin, J.N.; Bassett, S.; O'Brian, D.W. Quality indicators for hip and knee osteoarthritis management in New Zealand: a patient survey. N Z J Physiother. 2019;47:183-92.

56. Allison K, Setchell J, Egerton T, Delany C, Bennell KL. In theory, yes; in practice, uncertain: a qualitative study exploring physical Therapists' attitudes toward their roles in weight Management for People with Knee Osteoarthritis. Phys Ther. 2019;99:601-11.

57. Atukorala I, Makovey J, Lawler L, Messier SP, Bennell K, Hunter DJ. Is there a dose-response relationship between weight loss and symptom improvement in persons with knee osteoarthritis? Arthritis Care Res (Hoboken). 2016;68:1106-14.

58. Messier SP, Mihalko SL, Legault C, Miller GD, Nicklas BJ, DeVita P, et al. Effects of intensive diet and exercise on knee joint loads, inflammation, and clinical outcomes among overweight and obese adults with knee osteoarthritis: the IDEA randomized clinical trial. JAMA. 2013;310:1263-73.

59. Jacobs $L G$, Pringle MA. Referral letters and replies from orthopaedic departments: opportunities missed. BMJ. 1990;301:470-3.

60. Tobin-Schnittger P, O'Doherty J, O'Connor R, O'Regan A. Improving quality of referral letters from primary to secondary care: a literature review and discussion paper. Prim Health Care Res Dev. 2018;19:211-22.

61. Wong J, Tu K, Bernatsky S, Jaakkimainen L, Thorne JC, Ahluwalia V, et al. Quality and continuity of information between primary care physicians and rheumatologists. BMC Rheumatol. 2019;3:1.

62. Akbari A, Mayhew A, Al-Alawi MA, Grimshaw J, Winkens R, Glidewell E, et al. Interventions to improve outpatient referrals from primary care to secondary care. Cochrane Database Syst Rev. 2008;2008(4):CD005471.

63. Hawley S, Ali MS, Berencsi K, Judge A, Prieto-Alhambra D. Sample size and power considerations for ordinary least squares interrupted time series analysis: a simulation study. Clin Epidemiol. 2019;11:197-205.

\section{Publisher's Note}

Springer Nature remains neutral with regard to jurisdictional claims in published maps and institutional affiliations. 